\title{
Ideology in Reporting the 'Operation Cast Lead', a Transitivity Analysis of the Arab News and New York Times Reports
}

\author{
Umar Bello \\ English Language Center, Jubail Industrial College, Jubail, P.O. BOX 10099, Saudi Arabia \\ Email: bello_u@jic.edu.sa, bello.umar@gmail.com
}

Received: 08-01-2013

doi:10.7575/aiac.ijalel.v.3n.3p.202
Accepted: 13-02-2014

Published: 01-05-2014

URL: http://dx.doi.org/10.7575/aiac.ijalel.v.3n.3p.202

\begin{abstract}
This paper attempts to use Transitivity and Critical Linguistics to demonstrate that news is (or can be) socially constructed and that reality in the press is more about opinions and propositions than facts. The language that is used to represent people and events is chosen from options and choices within the linguistic system that may not be value-free or coincidental. These choices can seek to represent the world in a particular ideologically-enforced manner. The analysis done in this paper using transitivity framework indicates how grammatical resources like agency deletion, negative/positive representation of actors, foregrounding/backgrounding, nominalization and so on are used by both the New York Times and Arab News to foster ideological interests and to underscore their favored worldviews. In the Operation Cast Lead war between Israel and Hamas, the Arab News reports are shown to be very critical of Israel while defending Hamas. The New York Times, on the other hand, is shown as mitigating Israeli assaults and indicting Hamas mostly for the overall negative consequences of the war.
\end{abstract}

Keywords: operation cast lead, Gaza, Newyork Times, Arabnews, transitivity, critical linguistics, critical discourse analysis, nominalization, ergativity

\section{Introduction}

This paper adopts a critical linguistic approach to issues of news reports. News reports help today in shaping and sustaining the opinions of the powerful elements, groups and countries in the international community. These opinions are then passed off as the natural or the inevitable reality (Simpson, 1999). According to Fairclough $(1989,54)$ the effects of media power are cumulative, through the repetition of particular ways of handling an agency, particular ways of positioning the reader and so forth media discourse is able to exercise a pervasive and powerful influence in social reproduction because of the very scale of the modern mass media and the extremely high level of exposure of whole populations to a relatively homogenous output.

The linguistic framing of issues and the proliferation of a particular point of view all help in the interpretation of what constitutes reality to the general public. Chomsky (2004) in reference to the New York Times maintains that the paper by selection of topics, by distribution of concerns, by emphasis and framing of issues, by filtering information, by bounding of debate within certain limits. They determine, they select, they shape, they control and they restrict-in order to serve the interests of dominant, elite groups in the society

Taking cognizance of this crucial role of the media in the construction or construal of our realities (especially in the aspect of language use), Critical Linguistics offers a close contextual, interpretative and constructivist approach that may help in showing this discursive social reproduction.

The Palestinian issue has remained an important crisis that involves the sustenance of the views of the dominant political groups through a particular way of representing issues in the press and the political sphere. A model of reality appears to have been constructed and buoyed discursively which also helps in the interpretation of the crisis to (and by) the public. The Palestinian issue has defied solutions owing substantially to the way issues are (mis)represented. Herman $(2010,1)$ laments about the abortion of the moral instinct in the global community towards the Palestinian issue.

The most interesting and perhaps most important case of an aborted 'moral instinct' is that involving Israel, where the state has been engaged in a systematic policy of dispossession and ethnic cleansing of the Palestinians on the West Bank and in East Jerusalem for decades, not only without a meaningful response on the part of the Free World, but with steady support from the United States and spurts of approval and support from its democratic allies. The ability of the Western political leaders, media and humanitarian intellectuals to get enraged at approved villains like Arafat, Chavez, and Milosevic, while treating Begin, Netanyahu and Sharon kindly as statesmen deserving of economic and military aid and diplomatic support, is a small miracle of self-deception, advanced double standards, and moral turpitude. 
This abortion of the moral instinct requires the construction, sustenance and naturalization of a particular ideology or point of view which gradually becomes the norm. Van Dijk (2006) observes that ideology or world view can be critically analyzed linguistically by examining the context of the discourse, analyzing which groups, power relations and conflicts are involved, looking for positive and negative opinions about 'us' and 'them', spelling out the presupposed and the implied, and examining all formal structures that (de)emphasize polarized group opinions. This paper would thus look at an aspect of the Palestinian crisis using transitivity analysis with its concern about the social contexts and roles of textual participants and actions. This may help in possibly demonstrating how ideologies are framed and sustained discursively.

This introductory part of the paper will look at the context of the crisis and the backgrounds of the two newspapers in our analysis.

\subsection{Review of the International Press in Reporting the 'orient'}

In the past, the trend of reportage in the western press especially on international affairs is one that was based on the ideological dichotomy between the capitalist and the communist world. Now with the collapse of the Berlin Wall and the demise of the cold war, the ideological battle has shifted grounds to one involving the occident as a whole and the orient represented by the Islamic world (mostly Asian and Arab). It is an "us" versus "them" construction. This point is articulated in Chomsky and Herman's (1988) propaganda model where the "'enemy" is constructed and made the "scapegoat". It is important to realize that the dialectical relationship between the text as produced by the media and the society (Fairclough: 1991) plays an integral role in the construction of reality. The text is socio-culturally shaped but it also constitutes the society and culture, in ways which may be transformative as well as reproductive. In reporting the world, the western press tends to operate within the purview of an ideological milieu. Facts are built upon other facts in an intertexual chain on the part of the media while the consumers form mental pictures of events created and interpret what they consume from that in-built framework thus sustaining and updating the ideological point. In reporting the Arab world, the west appears to adopt a predetermined stereotypical perception of issues and roles which they place into some arbitrary patterns. Said (1979) argues that the language of orientalism plays a dominant role in bringing opposites as natural, ascribing reality and reference to objects thus essentializing them. Orientalism employs a narrative, which assumes a distinct social and cultural reality about the Orient, discovered by the efforts of orientalists (those who actually construct the terminology) and assumed to be true; a reality that is different from its counterpart, the West. The so-called "Orient" press on the other hand tends to be on the defensive parrying away the attacks directed at them by their Western counterparts. In this discursive field, "a terrorist", "a fundamentalist", "an extremist", "a fanatic" and pejorative terms like "rag heads" etcetera are terms mostly ascribed to Eastern (Arab) Muslims by the Western media while the converse of these terms are held true as belonging to them (the West). Wodak and Busch (2004) rightly maintain that the terrorist attacks of September 2011, reinforces anti-Islamic feelings and prejudices. Representations of the Muslims in the media generalize the fear of terrorism and attribute the phenomenon to Muslims.

The relevance of this short note is to give the ideological context upon which actions of the media may be based. Below are short histories and orientations of the two newspapers involved in this paper.

\subsubsection{The New York Times}

The New York Times is an American daily newspaper founded and continuously published in New York City since 1851. It is both the largest local metropolitan newspaper in the United States as well as the third largest overall behind The Wall Street Journal and USA Today. According to Caballero $(2010,43)$ "the New York Times boasts a daily circulation of 1.1 million, and 1.7 MILLION Sunday editions. It also ranks among the most popular internet news site. The Times is one of the leading newspapers in the US that exerts influence on a large segment of the population. This alone calls for heightened scrutiny of its contents" Regarding the coverage of the Middle East Crisis, the New York Times has been noted for its pro- Israeli stand which challenges its reputation as a newspaper of record. Makdisi (2007) in her article on the Los Angeles Times bemoans the fact that The Times is Israel's ally. She particularly indicts a Times editorial demanding that the Palestinians recognize Israel and its rights to exist. This is because, as she maintains, the formal diplomatic language of "recognition" is traditionally by one state with respect to another. It is literally meaningless for a non-state to "recognize" a state and that, in diplomacy, such recognition is supposed to be mutual. She points out that in order for Israel to earn its recognition, it would have to, simultaneously, recognize the state of Palestine. She further maintains that the Times consistently adopts Israel's language and hence points of view. This can be equated to Fairclough's (1995) discussion of intertexuality where the news voice can subtly transmute into the voice and point of view of the reported party.

Zelizer et al (2002) indicts the Times of what amounts to "geographical bias" because their ground coverage is done with their reporters filing their stories of Gaza and the West Bank from Jerusalem. They criticize the Times lack of empathy with the Palestinian people while at the same time showing a profusion of this emotion in the few cases where the Israelis are the victims. Zelizer et al (2002) further emphasizes the way terms are manipulated by the Times newspaper to show bias. They particularly label those engaged in violent acts against Israel as "terrorists" or "suicide bombers" while not using the same labels for Israelis doing the same to Palestinians. Occupied lands are replaced with "contested lands", "Israeli settlements" are replaced with "Israeli neighborhood". Civilian Israelis are called "dovish" and "peaceniks" but these terms are almost never used for peaceful Palestinians. To soften Israeli culpability in violent attacks, victims, are sometimes called "collateral damage" or are "caught in crossfire". They further indict the paper of the personalization of issues i.e. seeing certain individuals or groups as bearing individual responsibility for events that occur. Such tendency toward individual explanations rather than toward more complex historical and legal contexts 
neutralizes the broader complexities underlying the crisis in the region.

\subsubsection{The Arab News}

The Arab News is a Saudi daily. It is one of the two English-medium dailies in the whole of the Kingdom of Saudi Arabia, the other being the Saudi Gazette. It started publication on the $20^{\text {th }}$ of April, 1975. According to Prince Turki Al Faisal, in the $35^{\text {th }}$ anniversary edition of the newspaper, the paper starts from a humble background with readership not exceeding hundreds of people, but soon became the No 1 newspaper among its peers in the Middle East. It is the most widely circulated Middle East English newspaper after its Arabic sister publication in Western Europe. The paper's reader demographics has phenomenally widened since January, 2001 when it went online. In 2009, the paper had more than 153 million hits on its website. It is instructive to understand that the paper started publication following the 1973 war between Arabs and Israel as form of an English voice of the Arab world.

\section{Transitivity and Critical linguistics as theory and method}

Critical Linguistics emerges from the work of Fowler et al in 1979 in their book Language and Control. According to Fowler (1991), the aim of critical linguistics is most importantly to formulate a linguistic analysis of public discourse designed to get at the ideology coded implicitly behind overt propositions, to examine them particularly in the context of social formations. In the aspect of the press and news-making, this aim is much more germane. Hodge (1979) sees newspapers as providing only a partial version of the world because they select, reorganize, transform, distort and suppress realities with a view to underscoring their ideological interests. News is as such thought of to be socially constructed rather than a value-free capturing of events and people. Fowler (1991) maintains that news is more of "ideas", "propositions", "values", "ideologies" etc. The social construction of reality or news entails a subjective ontological interpretation of issues, people and events passed as the reality of things. He argues that news is socially constructed due to the following points. First, newspapers select what to report or what constitutes news among other occurrences. This selection is itself not done value-free as this may involve the exclusion of other issues that may be news worthy. Closely related to this is the issue of news values which mostly pander to arbitrary dominant interests. He also argues that newspapers operate with stereotypes which help in creating 'socially constructed mental pigeonhole' into which people and events are sorted. Our discussion earlier of the orientalist perception of the Arabs falls into this category. Fourthly, there is also the consideration of socio-economic values associated with the press which may influence their reportage. These constraints identified by Fowler would hamper any objective reportage of the press. So Critical Linguistics seeks " by studying the minute details of linguistic structure in the light of the social and historical situation of the text, to display to consciousness the patterns of belief and value which are encoded in the language - and which are below the threshold of notice for anyone who accepts the discourse as natural" (Fowler1991, 67).

The linguistic facility that best serves as the analytical tool kit for CL is transitivity (Fowler 1991). As Simpson (1993, 96) also puts "the transitivity model provides one means of investigating how a reader's or listener's perception of the meaning of a text is pushed in a particular direction and how the linguistic structure of a text effectively encodes a particular worldview"

Transitivity is better understood in the context of general clausal functions developed by MAK Halliday. Halliday (1994) maintains that the clause is a multifunctional construct consisting of three metafunctional lines of meaning. This notion is a departure from traditional grammar that only studies and analyzes a clause structurally. The three metafunctions of a clause involve the textual (clause as message), the interpersonal (clause as exchange) and the experiential (clause as representation). These three metafunctions conflate or map into each other in a single clause providing a tripartite dimensions of meaning.

Our basic concern, in this thesis, is the "experiential" also called the "ideational" clause. In this clause, our experiences are chunked into quanta of change by the grammar of the clause, and each quantum of change as a figure (of happening, doing, sensing, saying, being or having). All figures involve a process unfolding through time and participants being directly involved in this process in some way; and in addition there may be circumstances of time, space, cause, manner etc. All such figures are sorted out in the grammar of the clause. The clause here is thus a mode of reflection, of imposing order on the endless variation and flow of events. The grammatical system by which this is achieved is the Transitivity System. Transitivity, in essence, construes the world of experience into a manageable set of "process types" with each process providing its own schema for construing a particular domain of experience as a figure of a particular kind. The process types here are six as outlined by Halliday (1994). They are material, behavioural, mental, verbal, relational and existential. The three main processes are the material, mental and relational, while the other categories are found at the boundaries of these processes. However, the processes that are most germane to this research are the material, verbal and relational which mostly are used by journalists in reporting about events, issues and happenings. It is important to note also that the concept of transitivity in functional grammar involves the process, the participants in the process, and the circumstance associated with the process. The process is realized by a verbal group, the participants usually by a nominal group and the circumstance by an adverbial or prepositional group. The participants are further realized by more iconic names.

The participants in transitivity are not just "subjects" or "objects" as obtained in traditional grammar, but as entities with particular forms of functions. In the material clause that does with "happenings" and "doings", for instance, we have the agents, the goal, the beneficiary or the affected all depending on the sort of activity and valency represented. In traditional grammar, a verb is determined as transitive or intransitive depending on the construction of the action. 
Invariably, the concept of transitivity relates to "ergativity" in material clauses. Halliday (1994), states that all transitivity systems in all languages are some synthesis of these two semantic models of processes, the transitive and the ergative. According to Downing and Locke (2005), ergative pair also called (anti-causative) occurs when the affected object of a transitive clause is the same as the affected subject of an intransitive clause. In this example: I rang the bell, "the bell" is the affected participant, but in: "The bell rang" we have a state where "the bell" is the subject of the process "rang". Ergatively, "the bell" is only the medium through which the process is actualized, and the agent initiator is backgrounded. The test for recognizing an ergative pair is that the causative-transitive, two participant structure must always allow for the corresponding one participant, anti-causative structure (as in "I rang the bell' and 'the bell rang"). Halliday (1994) maintains that by interpreting processes ergatively and transitively, we will be able to understand many features of English grammar which otherwise remain arbitrary or obscure. The ergative system will certainly be crucial in the analysis of our data as a beneficial supplement, providing an extra perspective to the transitivity interpretation and reconstructing, as it were, the backgrounded elements in our textual analysis.

In these two headlines in my data: Israeli Troops Mass Along Border and Gaza Hospital Fills up, we would see how the agents in both clauses are obscured using an ergative analysis. "Israeli troops" is here only a medium because the troops do not have the power to simply "amass" themselves without a powerful agent i.e. the Israeli Government telling them to do so. So the reconstructed version should probably be Israel Masses Troops Along Border. In the other example, Gaza Hospital Fills Up the Agent, Gaza Hospital is a medium of a process with an agent. The "hospital" cannot just fill itself up! So the reconstructed larger picture is perhaps Patients/wounded civilians fill up Gaza Hospital

From the little explanation above, we can see how and why the use of both Critical Linguistics and Transitivity can help in trying to relate news reports to their social and ideological contexts.

\subsection{Why Headlines?}

The analysis of the news reports we have here will be based on headlines. Headlines, as we have read earlier, (using the macro structure rules) are the distillation or summaries of the news items involved. They are mostly graphically made prominent. Richardson (2007) maintains that headlines simultaneously do both semantic and pragmatic functions. Semantic, because they do referential work and pragmatic because they seek to alert the reader to whom the text is addressed. Van dijik (1988) on his part perceives that headline + lead summarize the news text and express the semantic macro structures of the news items. In the aspect of news perception, a news schema has already created a mental frame of the prominence of the headlines and leads. News headlines are first on top and, for that reason, are markers that monitor attention, perception and the reading process. Readers mostly come into contacts first with the headlines then the decision about whether to continue and read everything. But the headline already forms a mental model in the mind of its reader. Some only read the headlines and go away since they have gotten the basic 'gist' of the news According to White (1997), the nucleus of the English-language print media hard news report is most typically constituted by the combination of its headline and its opening sentence known to journalists as either the "lead" or the "intro". He states that this opening nucleus of headline plus lead acts to launch a reader immediately into the heart of the social-order disruption about which the report is organized. Bell (1991) maintains that headlines are a part of news rhetoric that is meant to attract the reader.

By and large, the preceding discussion is meant to justify the selection of this portion of news texts to be analyzed. Headlines, first, form the summaries of news items and they are, then, put in a schematic framework that makes them prominent and easily read, recalled and even believed.

\section{Data Analysis and results}

The data to be analyzed are headlines from the two newspapers i.e. Arab news and the New York Times. The newspaper reports covered the duration of the crisis that is between $27^{\text {th }}$ December to $18^{\text {th }}$ January as the warfare lasted. The reports are taken from the actual reports of the newspapers not adopted agency reports. Our concentration in the analysis is on the Participants realized by the noun phrases, Processes by the verbal phrases and Circumstances by the adverbial and prepositional phrases.

Material action processes encompass verbs of doing, and doing to. The participant roles involve an Agent, the Doer, or the one performing the action and the ones on the receiving end are the Affected participants or Patients. The material process generally involves actions.

A verbal process is the process of saying, and it exists on the borderline between mental and relational processes. Just like saying and meaning, the verbal process expresses the relationship between ideas constructed in human consciousness and the ideas enacted in the form of language. The participant who is speaking is called 'Sayer', the addressee to whom the process is directed is' Target', and what is said is the 'Verbiage' or the 'Said'. In this case, since it is a newspaper sort of discourse, we would assume that the unstated audience or Target is the newspaper's readers and the international community. According to Richardson (2007) verbal processes are significant in trying to analyze ideology especially in reported statements. The reporting clause of a statement can frame the reader's interpretations of what is reported.

Relational process of transitivity expresses the process of being. According to Kress (1979), relational processes are clauses in which the "process" takes the form of a relationship between two participating entities, or between one participating entity and an attribute. Both of these two types may have the verb 'be', which tends to obscure the difference between them. Simpson (1993) suggests that quite often these processes signal that a relationship exists between two participants, but without suggesting that one participant affects the other in anyway. 
Reah (2002) observes that, by selecting from the range of models (processes), the producer of a text can present the world to the reader with an ideological slant imposed upon it. People or regimes can be presented as actors or recipients of action, and they can be presented in terms of their behaviour or qualities. In the data we have, there are complex relational constructions where "attributes" are simply brought to the fore without their 'carriers' and the 'processes' known.

Generally these three clauses pertain to the use of action, reactions and state of affairs which are all relevant in the analysis of how a war situation as we have here is reported.

\title{
3.1 The Arab News
}

The Arab News has a total of 32 headlines with material 16 processes, 12 verbal and 4 relational .

\subsubsection{Material Processes in the Arab News}

\author{
1. Sun 28 Dec 2008,Israel rains death on Gaza. \\ 2. Thur 1 Jan 2009, Hamas keeps flag flying. \\ 3. Thur 1 Jan 2009,Saudi relief supplies reach Palestine. \\ 4. Thur 1 Jan 2009,'Israeli assault of Gaza empowers Hamas objective'. \\ 5. Fri 2 Jan 2009,Israel murders top Hamas leader. \\ 6. Sat 3 Jan 2009,Israeli jets blow up children. \\ 7. Sat 3 Jan 2009,Abdullah visits injured Palestinians. \\ 8. Sun 4 Jan 2009,Israeli terror unleashed. \\ 9. Tue 6 Jan 2009, Foreign journalists barred from Gaza. \\ 10. Wed 7 Jan 2009,Israeli terror in Gaza overshadows US-Gulf forum. \\ 11. Thur 8 Jan 2009,US-GCC forum ends with call for greater understanding. \\ 12. Fri 9 Jan 2009,UN halts work after Israeli attack. \\ 13. Mon 12 Jan 2009, Red Cross halts Gaza operation. \\ 14. Tue 13 Jan 2009,UN sets up Gaza probe \\ 15. Tue 13 Jan 2009,Israelis rain phosphorous bombs over children in Gaza. \\ 16. Fri 16 Jan 2009,Israelis bomb UN compound.
}

In the above list, we can see how agency and processes are distributed. We can see how "Israel" is made to appear the Agent of processes associated with violence. In sentences 1, 5, 6, 16 and 17, it is clearly shown how Israel is the Agent of processes of extreme violence. The representation of Israel here conjures up the image of not only extreme violence but callousness. It is instructive to know that the 'Patients' of the 'Processes' all appear to be civilians and children. In 6 and 16, we have processes like 'blow up' and 'rain' and the Patients are 'children'. As Simpson (1993) observes, in material processes, lexical choices are just as strong an indicator of the respective political stances adopted by newspapers. This representation draws up on the discourse of humanistic compassion about children which Israel is shown here as having flouted. This representation, also, clearly demonstrates that the war is far from the claim by Israel that it is a war on Hamas since the casualties are civilians. Hamas, on the other hand, is represented as heroic in two headlines ( 2 and 4), that, despite all the 'Israeli aggression', it is more empowered and more determined. In these two cases, although the Arab news is shown as trying to project Israel as savage, it is also trying to show that it is not achieving its aims with Hamas but rather inflicting injury on soft civilian targets. In 4, we have a nominalization i.e. "Israeli assault of Gaza", a notion that already appears as truth situation or an acceptable state of affairs (syntactically) that Israeli military activity is an "assault" on Gaza city and by implication the civilian population not on Hamas. This nominalization forms a notion that carries no responsibility regarding details. In 10 , we equally have another nominalization 'Israeli terror in Gaza' which also establishes a state that passes rather surreptitiously as an established thing or as the truth. These two nominalizations form part of the negative image of Israel formed by the Arab news.

In 8 and 9, we have passive formations where the actions of Israel are foregrounded without Agents. Here it is the action that is more important and needing to be highlighted. Though in 'Israeli terror unleashed' the agent is recoverable from both the context and the modifier so also is 'Foreign journalists barred from Gaza.' The international community is involved in 3, 7, 11, 12, 13 and 14 especially to indicate international outrage. Saudi Arabia is shown as initiating humanitarian assistance i.e. king Abdullah visiting the injured Palestinians flown to Saudi Hospitals and also the relief consignment reaching the Palestinians. The UN and the Red Cross, for instance, are shown as having to halt their actions due to Israeli 'aggression'.

From this analysis, it is immediately clear the world view that is attempted to be created by the Arab news in the reports. Israel is constructed as a bully and an aggressive coward attacking children and ordinary civilians. It is shown also as not being able to subdue Hamas; the only case shown is one about the murder of a Hamas leader in 5. Even here it suggests an act of overkill for a whole country's army to 'murder' a particular individual. Hamas, on the other hand, is painted in heroic and stoic light as not being able to be subdued by Israel. .

From this analysis, it is immediately clear the world view that is attempted to be created by the Arab news in the reports. Israel is constructed as a bully and an aggressive coward attacking children and ordinary civilians. It is shown also as not being able to subdue Hamas; the only case shown is one about the murder of a Hamas leader in 5 . Even here it suggests an act of overkill for a whole country's army to 'murder' a particular individual. Hamas, on the other hand, is painted in heroic and stoic light as not being able to be subdued by Israel. . 
3.1.2 Verbal Processes in the Arab News

1. Sun 28 Dec 2008, OIC, GCC denounce massacre in Gaza.

2. Tue 30 Dec 2008, Israel declares 'all-out war'.

3. Tue 30 Dec 2008. GCC denounces massacre.

4. Wed 31.Dec 2008,CAIR says Israel has turned Gaza into a giant jail.

5. Wed 31 Dec 2008, GCC appeals for end to massacre.

6. Fri 2 Jan 2009, Abdullah,Erdogan to discuss Gaza situation.

7. Fri 2 Jan 2009,king orders fundraising.

8. Sat 3 Jan 2009, Al-saudis asks Muslims to rally behind Palestinians.

9. Sun 4 Jan 2009,king,Erdogan discuss truce.

10. Sun 4 Jan 2009,OIC slams world silence on Gaza bloodbath.

11. Mon 5 Jan 2009,king tells Palestinians to stand united.

12. Tue 6 Jan 2009,kingdom denounces silence-Palestinian factions asked to unite.

The choice of who to quote is ideologically significant. It is instructive to know that 'Israel' is only quoted once but negatively. Supporters of Israel or Israel itself are not quoted. All others are the voices of anti-Israel that are used to sustain the negative impression established by the Arab News about Israel. There are three important configurations in the verbal processes here, namely: condemnation of the Israeli action, the voice of appeal for Palestinian and Muslim unity over the Gaza attacks, and the activities of the kingdom of Saudi Arabia in support of the people of Gaza. The 'target' of the 'verbiage', as we can see from the data, is mostly the international community with the exception of 7,10 and 11 . Here the targets are mentioned because they are intended to be specific by their 'Sayers'. All with the exception of number 2 are indirect quotations leaving the represented texts open to possible manipulation. The processes used here like 'denounce', 'slam', 'appeal', 'orders' are all qualifications or evaluations made to represent what people say and how they say them. Here there is a lot of room for personal bias, as I said earlier, subtly made into the point of view of represented 'Sayers'. It is also important to realize that the naming of Israeli attack as 'massacre' almost three times contribute in enriching the mental models already established in the minds of the Arab news audience regarding Israel thus perspectivizing their action as amounting to that i.e. massacre not self-defense or any less emotive term.

3.1.3 Relational Processes in the Arab News
1. Thur. $8^{\text {th }}$ Jan 2009 Road to hell
2. Thur. 15 Jan 2009, Grave assault.
3. Sat 17 Jan 2009,Sling shot versus gunshot.
4. Mon. 19 Jan 2009, Arab summit in Kuwait to discuss Gaza reconstruction.

In the first construction, Israeli action is qualified as 'grave assault' this is established through the byline: "GAZA CITY: Israel yesterday bombed the crammed Sheikh Radwan cemetery, sending body parts flying onto neighboring houses and blasting craters into the graveyard" in the second one we equally see as the Gaza war is likened to that between 'slingshot' and 'gunshot'. 'Slingshots' are known to be used by children in hunting, but 'gun shots' by adults. This configuration draws up the image of a war of unequal might and that of bullying. 3 shows an attempt to have a meeting by Arabs to reconstruct the 'destroyed' Gaza, while 4 is about Gaza being seen as road to hell due to a possible renewed Israeli military incursions. This is also recoverable from the byline: "GAZA CITY: Israel tentatively welcomed a proposal yesterday from Egypt and France for a Gaza cease-fire and briefly halted its offensive to allow aid to reach civilians, but top Israeli ministers yesterday approved an even tougher war to press ahead with its assault on Hamas" the underlined part of the byline is what prompted the headline "road to hell'. By and large, the Attributes drawn up in the relational processes appear all arbitrary since they have to

do with personal evaluations of a happening in which the newspaper already takes a stand. Drawing up relationships and associations between entities using 'be' verbs and the likes gives a lot of room for subjective analysis as shown in the above 'Attributes' and their (arbitrarily) selected 'Carriers'.

\subsection{The New York Times}

The New York Times has a total of 32 headlines with material processes taking about 24, verbal 7 and relational 2.

\subsubsection{Material Processes from the New York Times}

1. 27 Dec 2008, Israeli Attack Kills Scores Across Gaza.

28 Dec 2008, Israeli Troops Mass Along Border; Arab Anger Rises.

3. 28 Dec 2008 More THAN 225 DIE IN GAZA AS ISRAEL STRIKES AT HAMAS

4. 31 Dec 2008, In Dense Gaza, Civilians suffer.

5. 31 Dec 2008, An Egyptian Border Town's Commerce, Conducted Via Tunnels, Comes to a Halt.

6. 1 Jan 2009, In a Broadening Offensive, Israel Steps Up Diplomacy.

7. Jan 2009, Egypt Pressed on Gaza From Without and Within.

8. Jan 2009, Israeli Troops Launch Attack on Gaza.

9. Jan, 2009, escalation feared as Israel, continuing bombing, lets foreigners leave

10. Jan 2009, Gaza Hospital Fills Up, Mainly With Civilians. 
11. 4 Jan 2009, Israel Strikes Before an Ally Departs.

12. 4 Jan 2009, In Israel, Bloomberg Shows His Support.

13. 4 Jan 2009, Israeli Attack Splits Gaza; Truce Calls Are Rebuffed.

14. 4 Jan 2009, Israeli ground invasion cuts Gaza in two.

15. Jan 2009, Israel Deepens Gaza Incursion as Toll Mounts.

16. Jan 2009, Israeli Shells Kill 40 at Gaza U.N. School.

17. 6 Jan 2009, Israel Puts Media Clamp on Gaza.

18. Jan 2009, Israel Resumes Attack After Pause for Aid Delivery.

19. Jan 2009, Rocket Fire From Lebanon Unsettles Israel, but Fears of a Hezbollah Attack Subside.

20. Jan 2009, Call for Cease-fire Goes Unheeded.

21. 30 Jan 30 confirmed dead in shelling of Gaza family

22. Jan 2009, Israelis United on Gaza war as Censure Rises Abroad.

23. Jan 2009, Iran Gives Hamas Enthusiastic Support, but Discreetly Just in Case

24. 15 Jan 2009, Israel Shells U.N. Site in Gaza, Drawing Fresh Condemnation.

The above headlines from the New York Times are very different from those from the Arabnews. Israel is shown here as the Agents of some violence-related Processes, the Patients of the Processes are mystified or not clearly mentioned as in Arab News. Numbers are mostly used i.e. in 1, 3, 13 and18. The use of number here mitigates the poignancy of the 'savagery' through defacing identity by numeralization. 'Israel kills thirty Palestinians' is a world of difference from 'Israel killed 30'. Intransitive verbs are also used instead of transitives i.e. in 3, 'die' is used instead of 'kill', and in 8 'dead' is used instead of 'killed'. The implication here is that 'agency' is not clearly stated.

In 2, 4 and 8 , we have the ergative models. In 2, "Israeli troops" is here only a medium because the troops do not have the power to simply "amass" themselves without "a powerful agent" i.e. the Israeli Government telling them to do so. So the reconstructed version should probably be Israel Masses Troops Along Border. In 4, the Participant 'civilians' should be a 'medium' of a process at least in that context. This is where 'civilians' are mentioned as Participants and incidentally they are shown as if 'suffering' just on their own without an agent making them undergo the process. "Gaza Hospital" as the Agent of item 10 is a medium of a process with an Agent. The hospital cannot just fill itself up, so the reconstructed larger picture (avoided) is perhaps "Patients/wounded civilians fill up Gaza Hospital". There are also nominalizations in 5 and 19 that are of ideological significance. In 5, we have "An Egyptian border town's commerce conducted via tunnels" which establishes a state passed off as the reality and is made to serve as the agent of the process 'comes'. This fact regarding the usage of tunnels to conduct business is one of the reasons the operation cast lead was launched in the first place according to Israel. This nominalization talks about a fact without details and shows how a contested proposition is passed as a true state of affairs. In 19, we have two nominalizations: "Rocket fire from Lebanon" and "Fears of 'Hizbullah' attacks". These also establish facts without details and subtly make points that are of ideological essence. The first one indicates that Israel is also under an attack from some external Arab forces. In the second one, we equally have another nominalization which indirectly frames 'Hizbullah'. In 3 and 18, we also have 'circumstances' that are meant to 'neutralize' the action of Israel. "More than 225 die in Gaza" is immediately neutralized with "as Israel strikes at Hamas". The use of this 'circumstance' here suggests that the casualties are 'collateral damage' or 'caught in crossfire' and the intended target is Hamas. In 18, "Israel resumes attack" is also immediately neutralized with the circumstance "after pause for aid delivery". This one here attempts to give a human face to Israel saying, though, Israel attacks yet it, at the same time, shows humanitarian considerations. In general, the construction here attempts to capture realities, but at the same time acquit Israel in so many places.

\subsubsection{Verbal Processes in the New York Times}
1. $27^{\text {th }}$ Dec 2008, Israelis Say Strikes Against Hamas Will Continue.
2. $29^{\text {th }}$ Dec 2008, Israeli Foreign Minister says Hamas is to blame.
3. $30^{\text {th }}$ Dec 2008, Despite Strikes, Israelis Vow to Soldier On.
4. $8^{\text {th }}$ Jan 2009, Israel Condemns Vatican's 'Concentration Camp' Remarks.
5. $10^{\text {th }}$ Jan 2009, As Talks Falter, Israel Warns of More Extensive Attacks.
6. $13^{\text {th }}$ Jan 2009, Israel Says Hamas Is Damaged, Not Destroyed.
7. $17^{\text {th }}$ Jan 2009, Israel Declares Cease-fire; Hamas Says It Will Fight On.

The verbal processes we have above indicate how Israel is almost the only one quoted and represented and there is no any specific target other than the international community here or the paper's audience. In the first one, we have a state where Israel is talking about the strike against Hamas to be continued. This particular 'verbiage' is meant to further indicate that the war is against Hamas and all the strikes are meant for Hamas even where civilian casualties are heavily recorded. In the second one, we have a state where the Israeli foreign minister is quoted as categorically saying that Hamas is to blame. This indictment generally holds Hamas as even being responsible for all the actions committed by Israel. In 3, there is also another commentary by Israel showing that it would soldier on despite any attacks from Hamas. In the verbiage in four, we have a situation whereby talk is nominalized then used with a intransitive verb "falter" but the question is "who makes the talks falter?" is germane here. Israel is also shown as condemning the remarks of the Vatican regarding concentration camp. In 5, we see another ideologically important construction. In this construction, the headline is two-dimensional. It shows Israel in good light i.e. in its action of ending the war while 
Hamas's belligerent remark is juxtaposed to that of Israel's peaceful resolve. Essentially these constructions in the verbal transitivity do not show quotations or remarks from the pro Hamas or pro-Palestinian groups but appears as if it is the mouthpiece of the Israeli government.

\subsubsection{Relational Processes in the New York Times}

\section{27 Dec, 2008 Divisions deep at Arab League \\ 2. 12 Jan 2009, Israelis United on Gaza war (as Censure Rises Abroad)}

The relational processes captured here are only two. The first tries to indicate that there are deep divisions at Arab league or among the Arabs. This is to further indict the Arabs and show how they are lacking in unity. The converse of this is made true about the Israelis in the second construction. The Israelis are shown as having a single voice and appear to be united even as international censure continues to rise. Again this re-echoes the construction of binaries and of ideological opposites.

In conclusion, all these processes (from the Arab News and the New York Times) together give us a picture of how the two papers approach the issues they report. Both papers place emphases on the 'material' aspect of the processes indicating their concerns with the actions in the war, then followed by the verbal i.e. what the people say and how they say them, and then those of the relational which are few. The general representation by both papers can be likened to the use of different torches that simply flash areas that they would like us to see and those that should be hidden.

\section{Discussion \& Conclusion}

The central point of this paper is that news can be socially constructed and that newspapers report events not necessarily guided by the age-long journalistic ethos of objectivity but by their ideological preferences. Our above analysis which represents the overall reportage of events during the Operation Cast Lead incident in headlines shows that the two newspapers are different in their perceptions of the war. The AN has 32 headlines in which 24 are MP, 12 VP and four RP. The NYT has 33 headlines in which 24 are MP, 7 VP and 2RP. See figures 1 and 2 below for the percentages in pie charts:

\section{Transitivity in Arab news reports}
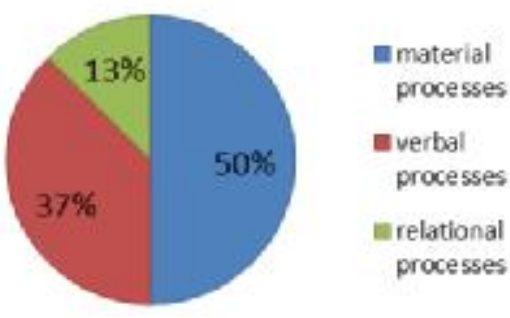

Figure 1. Transitivity in AN

\section{Transitivity in New York Times}

reparts

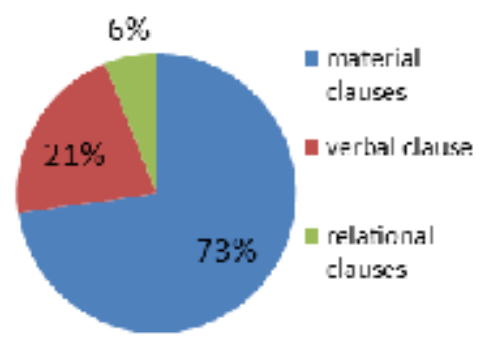

Figure 2. Transitivity in NYT

The preponderance of material processes in both papers indicates their interest in the actions of the war. The NYT is shown to have more interest in the actions of the war with $73 \%$ of its reportage related to that. In the aspect of the verbal processes, the AN has about $37 \%$ which is more than NYT's by about $16 \%$. The interest of the AN in the verbal process indicates the interest it probably has in the general commentary of those people against the war especially against Israeli action. Various bodies and political leaders are quoted and all seem to decry Israeli action. Quoted commentary from the NYT, on the other hand, is almost totally by Israel. This confirms Zelizer et al's (2002) view that NYT behaves as sometimes as if it is the mouthpiece of Israel. Moreover, the data generally typify Van Dijik's (2006) ideological square. The square essentially shows that ideological groups can assume binary positions vis-à-vis their opponents by: emphasizing the good properties/actions of the in-group,

emphasizing the bad properties/actions of the out-group, mitigating the bad properties/actions of the in-group and mitigating the good properties/actions of the out-group.

Both papers are shown as trying to assert their ideologies through such positionings by emphasizing the good aspects of those they support and deemphasizing their bad aspects while at the same time deemphasizing the good side of their ideological opponents while emphasizing their bad side. We have seen this framework shown over and over again through the facility of transitivity in our analysis. The Arab News tries so much to emphasize the bad of Israel while at the same time painting Hamas in good lights. In this we generally see AN's heroic positioning of Hamas while decrying Israeli attack as cowardly. 
The New York Times, on its part, is shown as trying to deemphasize the bad of Israel while subtly focusing on the ills of Hamas and indirectly trying to acquit Israeli action and focusing on the fact that Israel is fighting Hamas. Issues of such nature show that news is ideologically a priori. To the Arabnews, Israel will always be a 'villain' in whatever news it may appear in relation to military conflicts with the Arabs. Hamas would also always be a 'terrorist' to the New York Times whatsoever the reality may be. By and large, transitivity analysis coupled with Critical Lingusitic framework has shown that bias in the media can be established systematically. The notion that news is socially constructed holds true by this analysis. The papers virtually represent reality not as it is but as they would want it to be.

\section{References}

AMNESTY INTERNATIONAL USA. ISRAEL/GAZA: Operation 'Cast Lead'-22 Days of Death and Destruction. Report no. MDE 15/021/2009. www.amnestyusa.org (accessed April 29, 2010).

ARAB NEWS (Jeddah). (News Items culled). 12/27 2008 to $01 / 18^{\text {th }} 2009$.

Bell, A. (1991). The language of news media. Oxford, UK: Blackwell.

Dijk, T. A. (1988). News as discourse. Hillsdale, NJ: L. Erlbaum Associates.

Caballero, Jonas Xavier. (2010) "The Impact of Media Bias on Coverage of Catastrophic Events: Case Study From the New York Times' Coverage of the Palestine/Israel Conflict." B.Phil Diss. University of Pittsburgh.

Downing, A., \& Locke, P. (2006). English grammar: a university course (2nd ed.). London: Routledge.

Erakat, Noura. (2009) "The Operation Cast Lead: The Elusive Quest for Self Defense Under International Law." Rutgers Law Records 36. (accessed May 15, 2010).

Fairclough, N. (1989). Language and power. London: Longman.

Fairclough, Norman. (1995)Media discourse. London: Arnold.

Fowler, Roger, Bob Hodge, Gunther Kress, and Tony Trew. (1979) Language and Ideology. London: Routeledge and Kegan Paul.

Fowler, Roger. (1991) Language in the news Discourse and ideology in the press. London and New York: Routeledge.

Halliday, M. A. (1994). Functional grammar. London: Edward Arnold.

Herman, E. S., \& Chomsky, N. (1988). Manufacturing consent: the political economy of the mass media. New York: Pantheon Books.

Herman, Edward S. (2010) "Israeli Ethnic Cleansing and the Moral Instincts." Www.coldtype.net. (accessed July 15, 2010).

Makdisi, Saree. (March 11, 2007) "In the war of words, The Times is Israel's ally" (news article) Los Angeles Times: Los Angeles.

New York Times (New York). (News articles culled) 12/27 2008 to $01 / 18^{\text {th }} 2009$.

Reah, D. (1998). The language of newspapers. London: Routledge.

Richardson, J. E. (2007). Analysing newspapers: an approach from critical discourse analysis. Basingstoke [England: Palgrave Macmillan.

Said, E. W. (1979). Orientalism. New York: Vintage Books.

Simpson, P. (1993). Language, ideology, and point of view. London: Routledge.

Van Dijk, T. A. (2006). Ideology and discourse analysis. Journal of Political Ideologies, 11(2), 115-140.

Wodak, Ruth; Brigitta Busch (2004) Approaches to media texts. In: John Downing; Denis McQuail;

Philip Schlesinger; Ellen Wartella (eds.) Handbook of Media Studies. Thousand Oaks, London,

New Delhi: Sage, 105-123.

White, P.R.R. (1997) "Death, Disruption and the Moral Order: the narrative impulse in mass-media 'hard news' reporting." In Genres and Institutions: Social Processes in the Workplace and School, 101-33. London: Cassell.

Zelizer, Barbie, David Park, and David Gudelunas. (2002) "How bias shapes the news Challenging The New York Times' status as newspaper of record in the Middle East." Journalism 3(3): 283-307. 